\title{
$\mathrm{W}$-대역 수신기 모듈의 특성 측정
}

\section{Measurement of Characteristics of W-Band Receiver Module}

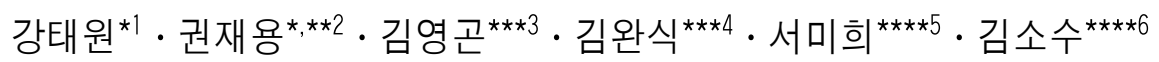 \\ Tae-Weon Kang ${ }^{* 1} \cdot$ Jae-Yong Kwon ${ }^{* * * *^{2}} \cdot$ Young-Gon Kim***3 $\cdot$ Wansik Kim ${ }^{* * * 4} \cdot$ Mihui Seo****5 $\cdot$ Sosu Kim****6

\section{요 약}

$\mathrm{W}-$ 대역 수신기 모듈을 제작하고 특성을 측정하였다. 믹서가 내장된 수신기 모듈의 잡음특성을 평가하기 위해 두 개의 표준잡음원, 즉 $\mathrm{W}$-대역 도파관 잡음원과 $3.5 \mathrm{~mm}$ 동축 잡음원을 사용하여 신호분석기의 잡음 측정부를 교정하였다. 신호 분석기의 스펙트럼 분석기능을 사용하여 중간주파수(IF) 출력전력 $P_{I d B, o u t}$ 과 이미지 저지 비를 측정하였다. 주파수 범위 $\left(f_{c} \pm 0.5\right) \mathrm{GHz}$ 에서 수신기 모듈의 이득은 $27 \mathrm{~dB}$, 잡음지수는 $9 \mathrm{~dB}$ 였다. 또한, 수신기 모듈의 1-dB 이득 압축 입력전력 $P_{I d B, i n}$ 과 $\mathrm{IF}$ 이미지 저지 비는 각각 $-11 \mathrm{dBm}$ 및 $13 \mathrm{~dB}$ 로 측정되었다.

\section{Abstract}

In this paper, a W-band receiver module is fabricated and its characteristics are measured. To evaluate the noise characteristics of the module that includes an embedded mixer, the noise-measurement part of a signal analyzer is calibrated using two standard noise sources: a W-band waveguide and a $3.5-\mathrm{mm}$ coaxial noise source. The image rejection ratio and $P_{\text {IdB,out }}$ at the intermediate frequency (IF), are measured using the spectrum analysis function of the signal analyzer. In the frequency range of $f_{c} \pm 0.5 \mathrm{GHz}$, the measured gain and noise figure of the module are 27 and $9 \mathrm{~dB}$, respectively. The 1-dB gain compression input power, $P_{I d B, i n}$, and the IF image rejection ratio are measured to be $-11 \mathrm{dBm}$ and $13 \mathrm{~dB}$, respectively.

Key words: Gain, Millimeter Wave, Noise Figure, Noise Source, Receiver Module

\section{I. 서 론}

$30 \mathrm{GHz} \sim 300 \mathrm{GHz}$ 범위의 밀리미터파는 파장이 짧아 회로나 시스템의 소형화는 가능하지만 대기나 수분에 의
한 감쇠로 전송거리는 짧다. 그중에서 W-대역은 (76 81) $\mathrm{GHz}$ 차량 충돌방지 레이다, $94 \mathrm{GHz}$ 보안 - 천문 - 국 방분야의 수동 이미징 등 다양한 분야에 활용되고 있다 ${ }^{[1]}$. 전자파를 이용하는 통신은 송수신용 회로소자, 부품, 그

\footnotetext{
「이 연구는 한국표준과학연구원 20011026 전자기 측정표준기술 고도화 과제 및 국방과학연구소 계약번호 $\mathrm{UC1} 170028 \mathrm{FD}$ 에 의하여 지원된 과제의 연구비로 연구되었음.」

*한국표준과학연구원 전자파표준그룹(Electromagnetic Wave Metrology Group, Korea Research Institute of Standards and Science)

**과학기술연합대학원대학교 측정과학과(Science of Measurement Department, University of Science and Technology)

***LIG넥스원(주)(LIG Nex1 Corporation)

****국방과학연구소(Agency for Defense Development)

1: 책임연구원(https://orcid.org/0000-0002-7457-6585), 2: 책임연구원(https://orcid.org/0000-0002-0572-1005),

3: 수석연구원(https://orcid.org/0000-0002-0969-8068), 4: 수석연구원(https://orcid.org/0000-0002-2198-8754),

5: 선임연구원(https://orcid.org/0000-0003-3441-0190), 6: 팀장(https://orcid.org/0000-0002-1110-7896)

- Manuscript received May 25, 2020 ; Revised September 20, 2020 ; Accepted November 6, 2020. (ID No. 20200525-043)

· Corresponding Author: Tae-Weon Kang (e-mail: twkang@kriss.re.kr)
} 
리고 이들을 통합한 모듈이나 시스템이 전체적으로 구성 되어야 가능하게 된다. 예를 들면 저잡음 증폭기 ${ }^{[2]}$, 원격 탐사 라디오미터를 구성하는 W-대역 수신기 ${ }^{[3]}$, 레이다용 단일칩 수신기 ${ }^{[4]}$, 수동 이미징 수신기 모듈 ${ }^{[5]}$ 등이 개발되 었다. 본 논문에서는 밀리미터파 대역 탐지 시스템 구성 을 위해 제작된 $f_{c} \mathrm{GHz}$ 수신기 모듈의 성능 측정방법 및 결과를 제시한다.

\section{II. 수신기 모듈}

본 논문에 제시하는 $f_{c} \mathrm{GHz}$ 수신기 모듈은 그림 1과 같 이 저잡음 증폭기, 믹서, 스위칭 감쇠기로 구성되어 있다. 믹서를 구동하기 위한 국부발진기(LO, local oscillator)와 $\mathrm{dc}$ 바이어스 전압은 수신기 모듈 외부에서 공급한다. 수 신기 모듈의 집적회로는 그림 2(a)와 같이 $0.1 \mu \mathrm{m} \mathrm{GaAs}$ pHEMT 공정으로 제작되었으며, 모듈의 물리적 크기는 $49 \mathrm{~mm} \times 35 \mathrm{~mm} \times 36 \mathrm{~mm}$ 이다.

\section{III. 수신기 모듈의 특성측정 및 결과}

제작된 수신기 모듈의 성능은 잡음특성과 IF출력 특성 으로 나누어서 측정하였다.

\section{3-1 잡음특성}

수신기 모듈은 주파수변환기인 믹서를 포함하고 있다.

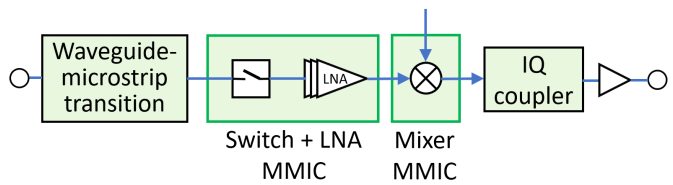

그림 1. 밀리미터파 수신기 모듈의 블록도

Fig. 1. Block diagram of the millimeter receiver module.

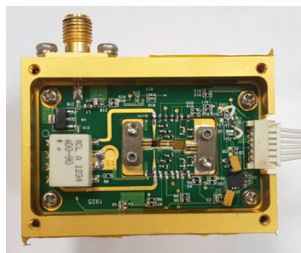

(a) 집적회로

(a) Integrated circuit

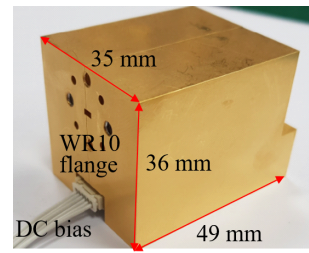

(b) 외관

(b) Exterior view
그림 2. 밀리미터파 수신기 모듈

Fig. 2. A millimeter wave receiver module.
믹서는 밀리미터파 입력(RF)을 국부발진기(LO)와 혼합하 여 낮은 대역의 IF 출력을 내는 주파수 변환 장치이다. 이 러한 주파수 변환 장치의 잡음 특성평가 방법은 문헌[6]에 상세하게 기술되어 있으며, 여기서는 측정학적으로 유의 미한 부분만을 다룬다. 그림 3 은 잡음특성 측정시스템을 보여준다. 먼저 측정시스템의 중심이 되는 $100 \mathrm{GHz}$ 급 신 호분석기의 잡음 측정부를 선택한다. 잡음 측정부는 2-포 트 기기의 이득과 잡음지수 측정결과를 화면에 보여준다. 측정 대상 수신기 모듈의 동작 주파수는 $\left(f_{c} \pm 0.5\right) \mathrm{GHz}$ 이 다. 예를 들어 측정주파수 $f_{c} \mathrm{GHz}$ 이면 신호분석기의 주요 파라미터는 다음과 같이 설정한다. $\mathrm{RF}$ 주파수 $f_{R F}=f_{c} \mathrm{GHz}$, $f_{L O}=\left(f_{c}-0.08\right) \mathrm{GHz}, f_{I F}=80 \mathrm{MHz}, \mathrm{USB}$ (upper sideband, 고 측 파대).

그림 3의 측정시스템을 교정하기 위해 W-대역 도파관 잡음원과 $3.5 \mathrm{~mm}$ 동축 잡음원을 사용하였다. $\mathrm{W}$-대역 도 파관 잡음원은 잡음원기시스템[7]으로 교정된 표준잡음원 과 잡음원교정시스템 ${ }^{[8]}$ 으로 교정되었다. $3.5 \mathrm{~mm}$ 동축 잡 음원은 영국 NPL(National Physical Laboratory)에서 교정 되었다. 교정값은 과도잡음비(excess noise ratio, $\mathrm{ENR})^{[9]}$

$$
E N R=10 \log _{10}\left(\frac{T_{e}-T_{0}}{T_{0}}\right)
$$

$T_{\mathrm{e}}=$ 잡음원의 등가 유효(available) 잡음온도, $T_{0}=$ 기준온도, $290 \mathrm{~K}$

로 주어진다. 잡음 측정부를 교정하기 전에 주파수별 $\mathrm{ENR}$ 값을 신호분석기에 입력하였다. 그림 3에서 믹서의 $\mathrm{RF}$ 입력은 $\mathrm{W}$-대역 도파관 잡음원에서 발생되는 잡음이 다. $\mathrm{LO}$ 는 $20 \mathrm{GHz}$ 신호발생기의 출력이 주파수체배기 $(\times 6)$

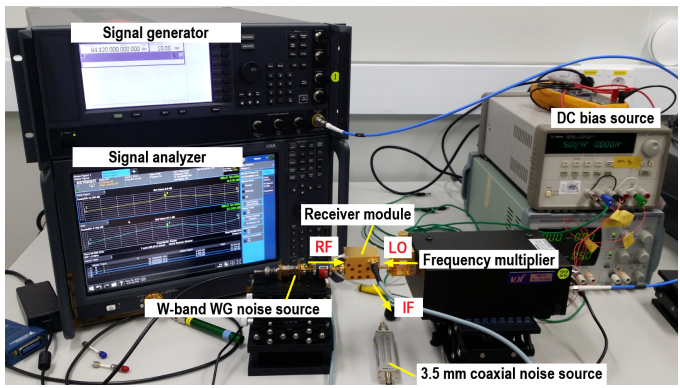

그림 3. 수신기 모듈의 잡음특성 측정시스템

Fig. 3. Measurement system of noise characteristics of the receiver module. 
를 통해 체배된 후 가변감쇠기로 조정되어 믹서에 공급 된다. 믹서는 LSB(lower sideband, 저 측파대)에 나타나는 이미지를 저지(image rejection)하도록 설계되었으며, IF 주파수는 $80 \mathrm{MHz}$ 이다. 그림 4는 $3.5 \mathrm{~mm}$ 동축 잡음원으로 IF 주파수에서 시스템을 교정한 후, W-대역 도파관 잡음 원을 이용한 측정시스템 구성도를 보여준다.

그림 5 와 같이 수신기 모듈은 주파수 $\left(f_{c} \pm 0.5\right) \mathrm{GHz}$ 범 위에서 잡음지수는 $9 \mathrm{~dB}$, 이득은 $27 \mathrm{~dB}$ 로 측정되었다. 유 사한 기법으로 개발된 다른 수신기 ${ }^{[4],[10]}$ 와 성능을 비교하 여 표 1에 제시하였다.

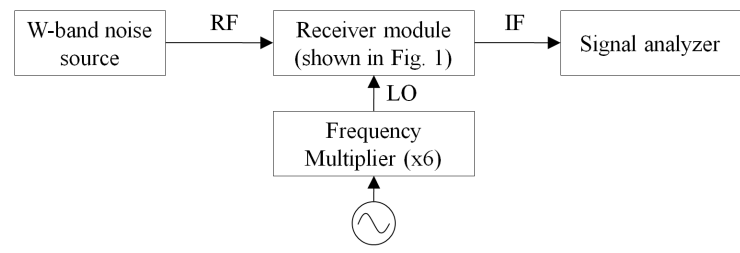

그림 4. W-대역 측정시스템의 다이어그램

Fig. 4. The diagram of the W-band measurement system.

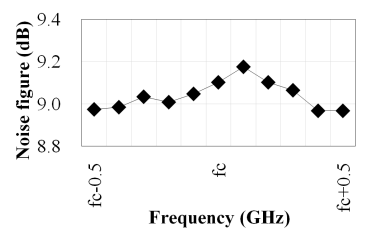

(a) 잡음지수

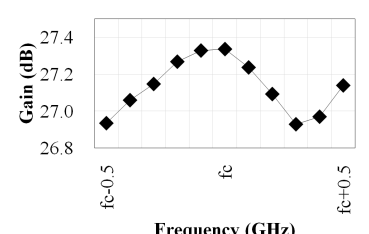

(b) 이득

그림 5. 수신기 모듈의 측정값

Fig. 5. Measured results of the receiver module.

표 1. W-band 수신기 모듈 성능 비교

Table 1. Performance comparison of W-band receiver modules.

\begin{tabular}{|c|c|c|c|}
\hline Quantities & This work & Reference [4] & Reference [10] \\
\hline Technology & $\begin{array}{c}0.1 \mu \mathrm{m} \mathrm{GaAs} \\
\mathrm{pHEMT}\end{array}$ & $\begin{array}{c}0.15 \mu \mathrm{m} \\
\text { GaAs pHEMT }\end{array}$ & $\begin{array}{c}0.1 \mu \mathrm{m} \text { GaAs } \\
\text { pHEMT }\end{array}$ \\
\hline Gain (dB) & 27 & 6 & 6 \\
\hline $\begin{array}{c}\text { Noise figure } \\
(\mathrm{dB})\end{array}$ & 9 & 5 & 5 \\
\hline $\begin{array}{c}\text { LO power } \\
(\mathrm{dBm})\end{array}$ & 10 & -1 & $\mathrm{NA}$ \\
\hline$P_{\text {ldB,in }}(\mathrm{dBm})$ & -11 & -13 & -15 \\
\hline
\end{tabular}

\section{3-2 IF 출력특성}

수신기 모듈은 IF $80 \mathrm{MHz}$ 에서 주파수 스펙트럼으로 출력된다. 신호분석기의 기본적인 스펙트럼 분석기능을 통해 출력 특성을 측정하였다. 신호분석기는 중심주파수 $80 \mathrm{MHz}$, 주파수 스팬 $5 \mathrm{MHz}$, 해상도 대역폭과 비디오 대 역폭은 각각 $47 \mathrm{MHz}$ 로 설정하였다. 그림 6에서 수신기모 듈의 $1-\mathrm{dB}$ 이득 압축 $\mathrm{IF}$ 출력 $P_{1 d B, o u t}$ 이 약 $16 \mathrm{dBm}$, 그림 5 (b)에서 이득이 약 $27 \mathrm{~dB}$ 이므로, 대응되는 IF 입력 $P_{I d B, i n}$ 은 $-11 \mathrm{dBm}$ 이다. 그림 7에서 이미지 저지비는 $13 \mathrm{~dB}$ 로 측정되었다. 수신기 모듈의 출력을 제어하기 위하여 스위 칭 감쇠기를 수신기 모듈 내부에 내장하여 제작하고, 그 성능을 평가한 결과, 그림 8 과 같이 약 $24 \mathrm{~dB}$ 의 감쇠량을 보여 설계조건에 부합되게 동작함을 확인하였다.

\section{$\mathrm{IV}$. 결 론}

$\mathrm{W}$-대역의 $f_{c} \mathrm{GHz}$ 에서 동작하는 수신기 모듈을 제작하

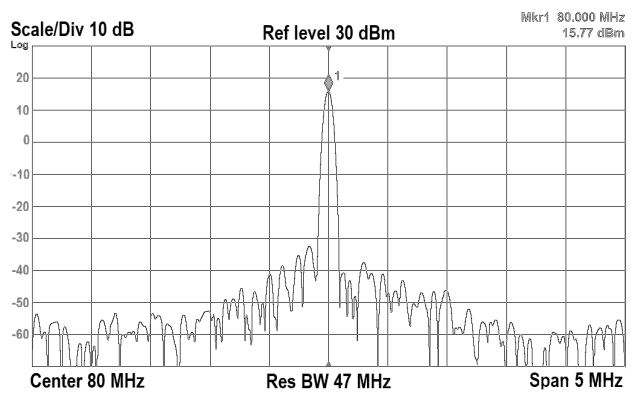

그림 6. 수신기 모듈 IF 출력단의 $P_{\text {IdB,out }}$ 측정

Fig. 6. Measured $P_{\text {IdB,out }}$ of the receiver IF output.

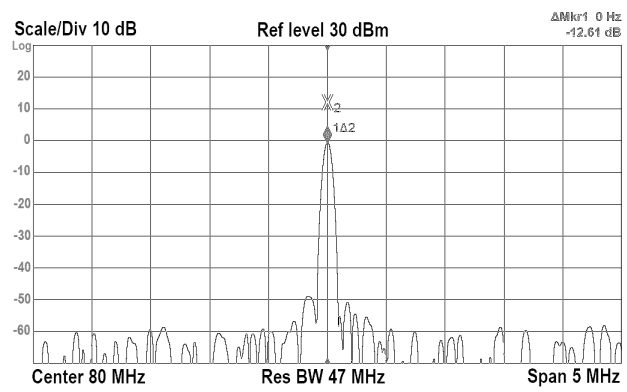

그림 7. 측정된 수신기 모듈의 이미지 저지 비

Fig. 7. Measured image rejection ratio of the receiver module. 


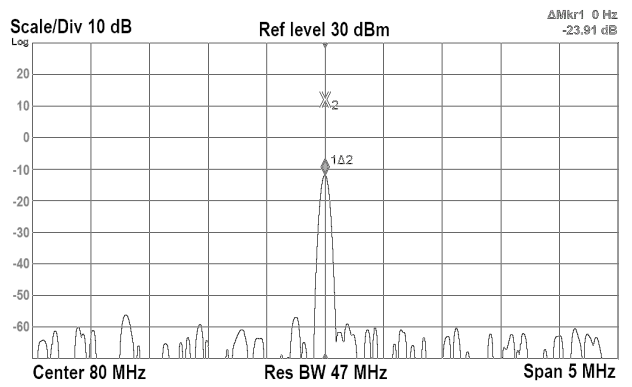

그림 8. 수신기 모듈에 내장된 감쇠 스위치에 의한 감쇠 량 측정

Fig. 8. The measured attenuation of the switch embedded in the receiver module.

고 성능을 평가하기 위하여 잡음특성 및 출력 특성으로 나누어서 측정하였다. 잡음특성은 표준잡음원을 사용하 여 신호분석기 잡음 측정부를 교정한 후 측정하였으며, 출력 특성은 신호분석기의 기본적인 스펙트럼 분석 기능 을 사용하여 측정하였다. 수신기 모듈은 주파수 $f_{\mathrm{c}} \mathrm{GHz}$ 에 서 잡음지수 $9 \mathrm{~dB}$, 이득 $27 \mathrm{~dB}$ 의 성능을 보였다. 수신기 모듈의 $1-\mathrm{dB}$ 이득 압축 입력전력 $P_{1 d B, i n}$ 은 $-11 \mathrm{dBm}$ 으로, $\mathrm{IF}$ 이미지 저지 비는 $13 \mathrm{~dB}$ 로 각각 측정되었다. 제작 - 평 가된 수신기 모듈은 $\mathrm{W}$-대역 신호탐지 시스템에 사용될 예정이다.

\section{References}

[1] S. Q. Xiao, M. T. Zhou, and Y. Zhang, Millimeter Wave Technology in Wireless PAN, LAN, and MAN, New York, NY, Auerbach Publications, 2008.

[2] H. W. Seo, J. H Park, J. S. Kim, and B. S. Kim, "Design of 94-GHz high-gain differential low-noise amplifier using 65-nm CMOS," The Journal of Korean Institute of Electromagnetic Engineering and Science, vol. 29, no. 5, pp. 393-396, May 2018.

[3] N. W. Moon, M. W. Lee, J. M. Jung, and Y. H. Kim, "Direct detection receiver for W-band radiometer," The
Journal of Korean Institute of Electromagnetic Engineering and Science, vol. 28, no. 5, pp. 426-429, May 2017.

[4] S. Lee, Y. Kim, S. Lee, K. Lee, W. Kim, and J. Jeong, et al., "W-band single-chip receiver MMIC for FMCW radar," Journal of the Institute of Electronics Engineers of Korea, vol. 49, no. 10, pp. 159-168, Oct. 2012.

[5] M. Sato, H. Sato, T. Hirose, T. Ohki, T. Takahashi, and K. Makiyama, et al., "Compact receiver module for a 94 GHz band passive millimetre-wave imager," IET Microwaves, Antennas and Propagation, vol. 2, no. 8, pp. 848-853, Dec. 2008.

[6] Agilent Technologies, Noise Figure Measurements of Frequency Converting Devices. [Online]. Available: http://iterature.cdn.keysight.com/litweb/pdf/5989-0400EN. pdf, Feb. 6, 2004.

[7] T. W. Kang, J. H. Kim, N. W. Kang, and J. S. Kang, "A thermal noise measurement system for noise temperature standards in W-band," IEEE Transactions on Instrumentation and Measurement," vol. 64, no. 6, pp. 1741-1747, Jun. 2015.

[8] T. W. Kang, J. H. Kim, J. Y. Kwon, and J. S. Kang, "Performance evaluation of a W-band waveguide noise measurement system for calibrating noise sources," The Journal of Korean Institute of Electromagnetic Engineering and Science, vol. 24, no. 2, pp. 180-188, Feb. 2013.

[9] R. J. Collier, A. D. Skinner, Microwave Measurements, 3rd ed. London, The Institution of Engineering and Technology, 2007.

[10] L. Li, Y. Gao, R. Qian, and X. Sun, "W-band four-channel receiver MMIC in $0.1 \mu \mathrm{m}$ GaAs PHEMT technology," in 2019 IEEE Asia-Pacific Microwave Conference(APMC), Singapore, Dec. 2019, pp. 15121514. 